\title{
Leisure activity and well-being among the elderly in Taiwan: Testing hypotheses in an Asian setting
}

\author{
ZACHARY ZIMMER ${ }^{1}$ \& HUI-SHENG LIN $^{2}$ \\ ${ }^{1}$ Population Studies Center and Department of Sociology, University of Michigan, and Centre \\ on Aging, University of Victoria; ${ }^{2}$ Research and Planning Division, Taiwan Provincial \\ Institute of Family Planning, The Republic of China
}

\begin{abstract}
Studies conducted in Western nations suggest hypotheses regarding the relationship between leisure activity and well-being among older adults. For instance, leisure activity is found to increase feelings of emotional well-being, and there are gender differences in both the types of activities in which elders tend to engage and their subsequent influences. This study attempts to verify these relationships among a sample of 4,049 Taiwanese elders (age $60+$ ). Analyses show that men participate in most leisure activities with greater frequency than women; physical activity has the strongest positive influence on emotional well-being; contemplative activity, the only pursuit in which women out-participate men, displays a negative effect for women, and; the impact of different activity types vary by gender. These results both substantiate and refute hypotheses developed in the West, suggesting cultural variation in the impact of activity. Gender differences are explained in the context of role expectations and self-concept development.
\end{abstract}

Key words: Life satisfaction, Well-being, Activity participation, Leisure activity, Taiwan, Elderly

\section{Introduction}

Many social theories and hypotheses in the field of gerontology have been developed through empirical analyses of North American and European samples. Few studies attempt to verify these suppositions in settings where social structures and role expectations differ. While some hypotheses may stand the test of cross-cultural validation, others may be more culturally dependent, but testing for them is no doubt advantageous to theory building.

In the West, leisure activity has been found to be an influential determinant of successful aging, although there are distinct participation differences between men and women elders and variations in the subsequent effects on emotional well-being. The Activity Theory of Aging, with its emphasis on role enhancement and development of self-concept through activity which promotes social integration, provides one explanation for the association. Researchers also point to the potential of leisure activity to enhance 
well-being through psycho-social processes such as feelings of competency, control and self-efficacy. This paper attempts to verify these commonly accepted notions in an Asian setting.

A rapidly modernizing society in Taiwan may lead some to assume that social structures which influence the relationship between activity and wellbeing are no different than those observed elsewhere. However, Taiwanese elders have been brought up in a very different cultural setting and role expectations which are dissimilar from those previously observed.

\section{Development of hypotheses}

Accounting for factors which influence the well-being of seniors has been a much researched topic. Demographic characteristics, such as income and marital status, health status, and social integration characteristics, have all been shown to exhibit important relationships with measures of well-being, life satisfaction and depression (see, for example: Chappell 1992; Doyle \& Forehand 1984; Duff \& Hong 1982; Kennedy, King \& Muraco 1983; Lee 1978; McKenzie \& Campbell 1987; Palmore \& Kivett 1977).

Research has generally demonstrated that participation in leisure activity is also a consequential determinant of successful aging. Markides \& Martin (1979), for example, found activity to be the most important predictor of life satisfaction. Fly, Reinhart \& Hamby (1981) found that activity correlates positively with life satisfaction and negatively with feelings of alienation. Kaufman (1988) showed leisure to be inversely related to levels of anxiety. DeCarlo (1974) asserted that life-long active participation in recreation has overall beneficial influences on well-being in old age. The conclusion that leisure activity has at least some beneficial impact on the lives of elders is rarely disputed.

One explanation accounting for this relationship relies on opportunities for social integration and its implications for role enhancement. The Activity Theory of Aging is often referred to in this context. This theory asserts that activity provides reinforcing role supports necessary for the maintenance of a positive self-concept which is associated with high life satisfaction (Knapp 1977; Lemon, Bengtson \& Peterson 1972). 'The greater the frequency of activity, the greater the opportunity and probability that role supports will result from the interaction' (Lemon, Bengtson \& Peterson 1972: 514). In other words, activity which is social in nature allows an individual to develop and enhance well-being through role continuity and the development of a sense of self.

Although the Activity Theory has received only moderate empirical support (see, for example: Longino \& Kary 1982; Steinkamp \& Kelly 1987), the 
beneficial aspects of social integration have been verified (Iso-Ahola 1989). Individuals tend to describe leisure activities which involve social interaction as the most satisfying of leisure experiences (Crandall 1979). Social activity has been shown to be particularly useful for those who suffer from chronic ailments typical in older ages, such as arthritis (Zimmer, Hickey \& Searle 1995). Social interaction promotes feelings of self-esteem while negating feelings of loneliness and isolation which are not conducive to psychological well-being (Iso-Ahola 1994). Others view the subjective quality of interaction or satisfaction with social activity as mediating variables through which participation influences well-being (Russell 1990; Steinkamp \& Kelly 1987).

A second explanation for the beneficial impact relies on the psycho-social mechanisms which are involved with leisure activity participation. In particular, leisure activities which tend to promote feelings of competency, accomplishment, self-efficacy and mastery over one's environment are thought to be particularly useful for positive psychological development in older adults (Iso-Ahola, LaVerde \& Graefe 1989). According to Csikszentmihalyi (1994), these types of activities promote 'flow experiences', which mentally involve, absorb and challenge an individual so as to produce an enhanced awareness of their environment. This perspective is useful in explaining the psychological advantage of participating in creative or physical pursuits (see, for example, Stewart \& King 1991), although the benefits of social activity can be similarly viewed. As Jackson \& Lilley noted, 'leisure provides a social role continuity for retired people as well as a social arena in which they can exercise competence and experience achievement and recognition' (Lilley \& Jackson 1990: 9).

The above discussion suggests that various types of leisure activities may operate to enhance well-being through different mechanisms, yet much previous research conceptualizes activity as being unidimensional in nature. In fact, studies which divide activity into components reveal that different types may have varying influences. Knapp (1977), for example, showed that solitary activities are not significantly related to two composite measures of well-being, while Lemon, Bengtson \& Peterson (1972) found social activity with friends to be the only activity type which benefits elders. Longino \& Kart (1982), on the other hand, provided strong support for a positive effect of informal activity, but a negative influence of formal activity, based on data from a retirement community. Moreover, Morgan, Dallosso, Bussey, Ehrahim, Fentem \& Arie (1991) examined several activities using a factor analysis procedure which confirmed that activity is not a homogeneous construct and can be divided into several components. This suggests the need for a distinction between different types of activity participation (Pohjolainen 1991). 
Despite the general view that leisure activity has favourable effects on elders as an aggregate group, a number of studies have demonstrated distinct gender differences. For example, Keith (1980) noted that men gain more from outdoor and maintenance activities while women more likely benefit from social pursuits. Lomranz, Bergman, Eyal \& Shmotkin (1988), found that although elderly men benefit from both outdoor and indoor recreation, among women, positive influences are found for indoor activities only. In looking at compulsory physical activity, Morgan et al. (1991) found that only men profited emotionally from increased participation.

Various suggestions have been advanced as to why men and women benefit differently from leisure. Lomranz et al. (1988) proposed that aging involves greater change for men than for women. Traditionally, men retire from jobs and begin to participate in new leisure activities, while for women, old age presents a greater continuity. The result is that activity has a more direct adaptive and emotional implication for men than for women. Morgan et al. (1991) stated that women are probably less able to select freely the activities in which they engage and therefore are more likely to be involved in indoor pursuits. Because activity is more imposed for women, they are less likely to accrue emotional benefits and, in fact, some activities may act as an impediment to successful aging.

Differences found in the effects of leisure activity on men and women do not necessarily run contrary to the theoretical interpretations reviewed above. If, as Keith (1980), suggested, the association between leisure and well-being reflects differences in socialization and traditional sex roles, it is likely that women are more apt to gain a greater sense of self-worth from activities which are social in nature and emphasize formal or informal interaction since women are more likely to be involved in these types of groups throughout their lives. In contrast, men are more likely to benefit from active instrumental leisure pursuits in which they participate alone and from doing chores around the house such as maintenance tasks, since they have leamed to develop a sense of self and gain feelings of competency and accomplishment through these types of activities. This leads to the likelihood that men and women also differ in the types of leisure activities which they tend to pursue, with women being more apt to involve themselves socially, while men are more likely to partake in solitary and physical pursuits.

As can be seen from the above review, research on the influence of leisure activity has been successful in establishing several hypotheses. Four of these are as follows:

1. Leisure activity is not a homogeneous construct and can be divided into several distinct components. 
2. Men and women tend to participate in different types of leisure activities. In particular, women tend to participate more often in social activities and indoor activities, while men participate more often in activities which are physical and solitary in nature.

3. Leisure activity has an overall independent positive influence on the wellbeing of elderly.

4. Leisure activity influences the well-being of men and women differently. Men benefit from physical activities but not from social activities while women benefit from social activities more than men.

These hypotheses have been developed almost exclusively with reference to North American seniors. There is a need now to expand the examination to determine whether they are universal cross-culturally. The analysis to follow will test these hypotheses using a sample of elders from Taiwan.

\section{Data and measures}

The data for this analysis come from the ' 1989 Survey of Health and Living Status of the Elderly in Taiwan', a random sample of 4,049 elders, age 60 and older, living in Taiwan, conducted by the Taiwan Provincial Institute of Family Planning in conjunction with the Population Studies Center at the University of Michigan. This survey involved personal interviews conducted in the home of a respondent. The response rate for this study was an extraordinarily high $92 \%$, ensuring accurate representation. The low refusal rate also ensures generalizability of the findings to the total population of elders in Taiwan.

Respondents in this study were asked whether they agree or disagree with a series of ten statements related to life satisfaction. The number of positive responses to these items are added to create a composite index of well-being ranging from 0 to 10 . The items included statements such as: my life could be happier than it is now; as I look back on my life I am fairly well satisfied; I have always felt interested in the things I have done. The mean well-being score is 6.2 and the standard deviation is 2.5 .

Leisure activity is measured by the frequency of participation, measured on a scale of 1 to 4, in ten pursuits. These are: participating in sports, gardening, going for walks, handicrafts, hobbies, reading, sitting and thinking, worshipping, playing games and socializing. For the first three items, response categories are: never, rarely, sometimes or often. The other items have response categories of: never or seldom, less than once a week, one to two times a week or almost every day. It is reasonable to assume that although the response categories differ, they are closely related, and hence the ten items are considered together. 
The activities referred to in this analysis are meant to represent a variety of pursuits normally considered to be conducted during free-time for leisure purposes. Other daily activities, such as those that are more mandatory in nature, are not included, despite the fact that all activity may have implications for well-being. Hence, the findings and discussions will be limited in this fashion. It should also be noted that, as yet, there are few rigorously tested and agreed upon leisure activity scales. Therefore, respondents were asked about pursuits that were thought to allow for differentiation among a number of frequently pursued activities and between major categories of leisure.

To study the influence of activity on well-being it is important to control for a series of other factors which are often associated with well-being. In this analysis, various demographic, health status and social network factors are considered. Demographic variables include age and years of education, both measured continuously, marital status, measured as married or other, and an income variable representing level of income on a seven point scale. A total of $13.2 \%$ of men and $13.9 \%$ of women do not report a level of income. Missing values for income are replaced by a mean income level given the marital status and sex of the respondent. For example, an unmarried woman with missing income data is given the mean income value for unmarried women in the study. This strategy provides a more accurate replacement value than a simple mean substitution. Missing data is not problematic for other variables utilized in this study.

In order to tap the range of health issues faced by elders, three measures of health status are utilized. The number of chronic conditions is calculated by adding the number of affirmative responses to a set of 30 health conditions such as: arthritis, high blood pressure, diabetes, etc. An index for ADL difficulty is computed by adding the amount of difficulty, measured on a scale of 1 to 4 , in conducting nine daily living tasks, with the sum divided by the number of applicable responses, creating an index ranging in score from 1 to 4 . These include items such as: climbing 2 to 3 flights of stairs, walking about 200 to 300 meters, reaching up over your head, etc. Finally, a five point self-assessed health item, often used in gerontological research, is included. Here, respondents rate their own health as excellent, very good, good, fair or poor.

Two social network variables are included, one being objective, the other a subjective social integration measure. Objective social network is measured by household size. Subjective social integration is measured by a composite index of satisfaction with social contact. Respondents were asked if they are very satisfied (score of 3 ), satisfied (score of 2) or not satisfied (score of 1 ) with the emotional support received from their (a) spouse, (b) children, childrenin-law and grandchildren, and (c) friends, neighbours and other relatives. 
Table 1. Means and standard deviations of controls by gender

\begin{tabular}{lrrrrr}
\hline & \multicolumn{2}{l}{ Women } & & \multicolumn{2}{l}{ Men } \\
\cline { 6 - 6 } \cline { 5 - 6 } & Mean & s.d. & & Mean & s.d. \\
\hline Demographic variables & & & & \\
$\quad$ Age & 68.92 & 6.65 & & 67.73 & 6.23 \\
$\quad$ Marital status (1 = married) & 0.51 & 0.50 & & 0.74 & 0.50 \\
$\quad$ Income level & 2.96 & 1.57 & & 3.84 & 1.60 \\
$\quad$ Years of formal education & 1.73 & 3.26 & & 5.37 & 4.81 \\
Health status variables & & & & \\
$\quad$ Number of conditions & 4.22 & 3.08 & & 3.24 & 2.75 \\
$\quad$ ADL difficulties index & 1.61 & 0.74 & & 1.35 & 0.62 \\
$\quad$ Self-assessed health & 2.95 & 1.02 & & 2.52 & 1.09 \\
Social network variables & & & & \\
$\quad$ Satisfaction with contact & 2.14 & 0.47 & & 2.18 & 0.50 \\
$\quad$ Household size & 5.37 & 3.08 & & 4.80 & 3.17 \\
\hline
\end{tabular}

Amount of satisfaction is the sum of these three items, divided by the number of applicable responses, creating an index ranging in score from 1 to 3 . In a case where one or more of the responses are not applicable, a mean is calculated using the applicable items only.

Since household sizes are relatively large in Taiwan, and individuals live more often in extended family settings than in the West, it is appropriate and advantageous to focus social network and support measures mainly on family interaction. It is thus assumed that much of the social support provided to elders in Taiwan is provided through familial interaction. There may be some disadvantage to ignoring outside forms of support, such as support from outside institutions, like churches or clubs. More specifically, such outside forms of support tend to fulfil alternate functions than familial interaction. However, it should be noted that one of the social support items includes support from non-relatives (friends and neighbours), and some degree of overall social interaction is captured in the social activity item.

Finally, the gender distribution of this sample is $57 \%$ men. Because of mass immigration of men from mainland China, Taiwan is one of the only countries in the world where elderly men outnumber elderly women. In addition, two of the above described measures, in particular, also display mean values very different from what would be expected in North American or European samples. Specifically, mean years of formal education (3.8) is much lower and household size (5.0) is much higher than would be expected in the West. For descriptive purposes, Table 1 displays means and standard deviations of the study control variables for men and women separately. 
Table 2. Principal component factor analysis of leisure activity items*

\begin{tabular}{|c|c|c|c|c|}
\hline & \multicolumn{4}{|c|}{ Factor patterns } \\
\hline & 1 & 2 & 3 & 4 \\
\hline \multicolumn{5}{|l|}{ 1. Physical activities } \\
\hline Sport & 0.74 & & & \\
\hline Walking & 0.63 & & & \\
\hline Gardening & 0.60 & & & \\
\hline Eigenvalue & 2.0 & & & \\
\hline Pct. of variance & 19.8 & & & \\
\hline \multicolumn{5}{|l|}{ 2. Creative activities } \\
\hline Games & & 0.63 & & \\
\hline Reading & & 0.60 & & \\
\hline Hobbies & & 0.58 & & \\
\hline Handicrafts & & 0.52 & & \\
\hline Eigenvalue & & 1.3 & & \\
\hline Pct. of variance & & 12.8 & & \\
\hline \multicolumn{5}{|c|}{ 3. Contemplative activities } \\
\hline Thinking & & & 0.76 & \\
\hline Worshipping & & & 0.75 & \\
\hline Eigenvalue & & & 1.1 & \\
\hline Pct. of variance & & & 11.0 & \\
\hline \multicolumn{5}{|l|}{ 4. Social activities } \\
\hline Socializing & & & & 0.88 \\
\hline Eigenvalue & & & & 1.0 \\
\hline Pct. of variance & & & & 9.6 \\
\hline Total explained varia & & & & \\
\hline
\end{tabular}

${ }^{*}$ Only rotated factor scores of 0.5 or higher are displayed.

Note that there are considerably wide gaps in the mean years of education for men and women (5.4 and 1.7 respectively) and in the proportion who are married ( 0.74 and 0.51 respectively). Relatively substantial differences also exist in terms of levels of income, chronic conditions and household sizes. It is likely that these factors would influence differences in the frequency of participation in some types of leisure activities through knowledge and availability of activities, and the ability or opportunity to participate.

\section{Analysis}

In order to determine whether activity for elderly in Taiwan is a homogeneous construct, the ten leisure activities were examined by a principal component factor analysis using varimax rotation. The results are seen in Table 2 . The first 
hypothesis regarding the heterogeneous nature of leisure activity is confirmed. The factor patterns display four interpretable and distinct factors with a total explained variance of $53.1 \%$. The first factor is comprised of participation in sport, walking and gardening. These three activities all involve a degree of physical and ambulatory movement and are therefore labelled as physical activities. The second factor is labelled creative activities and are made up of playing games, reading, doing hobbies and handicrafts. The third factor consists of thinking and worshipping. These are more sedentary activities, but also involve a degree of introspection and are therefore labelled contemplative activities. The final factor is made up of only one item, socializing, and is labelled social activities. This last factor still explains a fair proportion of the variance $(9.6 \%)$.

The results of the factor analysis are subsequently used to combine items into four indices of activity in order to create categories of activity for further analysis. That is, the frequency scores for each activity within leisure categories identified by the factoring solution have been added and divided by the number of responses to create four indices which range in score from 1 to 4 . Each index represents the frequency with which an individual engages in that category, with 4 indicating maximum participation. ${ }^{1}$

It may be argued that certain activities contained within the same index represent different forms of recreation. For instance, reading and hobbies are both considered within the creative activity index despite obvious differences between these types of activities. Similarly, reading could just as easily be conceptualized as a contemplative activity, just as gardening could be considered to be related to hobbies. Although there are obvious differences between all of the activities, the factor solutions suggest that there are strong links between certain items, and these links are summarized by using the broader definitions of recreation. In other words, these groupings provide a convenient way of summarizing the activity interests of Taiwanese seniors, and the definitions applied to them simply provide a convenient way of conceptual-

\footnotetext{
${ }^{1}$ The leisure activity indices created rely on the results of the factor loadings using the aggregate sample. Further analyses, not reported in tabular form, disaggregated the sample by gender. A three factor solution was derived for both genders with identical patterns. A fourth factor was borderline in both cases. For the three factor solution, the social activity item loaded together with the three physical activity items for both genders. The remaining two factors were identical to those reported for the aggregate analysis. Four factor solutions presented slight variations between men and women. The various factor patterns were subsequently tested in a similar fashion as the analysis that will be presented here with no changes to the resultant interpretations. We conclude that the aggregate patterns are adequate for subdividing activity types and do not confound results. Moreover, separating social interaction from more physical pursuits appears to make intuitive sense, and the independent influence of social activity on well-being is an association found to be important in previous research therefore worth highlighting.
} 
Table 3. Frequency of participants index scores and participation in individual leisure activities by gender

\begin{tabular}{|c|c|c|c|c|c|c|c|}
\hline & \multicolumn{3}{|l|}{ Men } & \multicolumn{3}{|c|}{ Women } & \multirow[b]{2}{*}{$t$ value } \\
\hline & Mean & $\begin{array}{l}\% \text { at least } \\
\text { weekly }\end{array}$ & $\begin{array}{l}\% \\
\text { daily }\end{array}$ & Mean & $\begin{array}{l}\% \text { at least } \\
\text { weekly }\end{array}$ & $\begin{array}{l}\% \\
\text { daily }\end{array}$ & \\
\hline 1. Physical activities & 2.27 & - & - & 1.93 & - & - & $12.97^{*}$ \\
\hline Sport & 1.80 & 26.2 & 14.5 & 1.48 & 15.5 & 10.1 & $9.22^{*}$ \\
\hline Walking & 3.00 & 66.7 & 52.5 & 2.54 & 51.9 & 36.9 & $10.33^{*}$ \\
\hline Gardening & 2.06 & 35.5 & 26.9 & 1.77 & 25.3 & 17.9 & $7.35^{*}$ \\
\hline 2. Creative activities & 1.56 & - & - & 1.16 & - & - & $28.84^{*}$ \\
\hline Game & 1.25 & 8.1 & 2.3 & 1.05 & 1.7 & 0.4 & $12.69^{*}$ \\
\hline Reading & 2.61 & 54.2 & 49.3 & 1.42 & 14.2 & 12.1 & $30.94^{*}$ \\
\hline Hobbies & 1.19 & 6.1 & 3.1 & 1.08 & 2.6 & 1.7 & $6.73^{*}$ \\
\hline Handicrafts & 1.17 & 6.2 & 3.4 & 1.10 & 3.1 & 1.6 & $4.30^{*}$ \\
\hline 3. Contemplative activities & 1.79 & - & - & 2.04 & - & - & $8.36^{*}$ \\
\hline Thinking & 1.86 & 29.9 & 16.2 & 1.95 & 32.7 & 16.8 & 2.18 \\
\hline Worshipping & 1.69 & 21.9 & 17.1 & 2.12 & 36.7 & 27.9 & $10.76^{*}$ \\
\hline 4. Social activities & 2.62 & - & - & 2.48 & - & - & $3.30^{*}$ \\
\hline Socializing & 2.62 & 65.9 & 39.0 & 2.48 & 51.9 & 36.1 & $3.30^{*}$ \\
\hline
\end{tabular}

${ }^{*} p<0.01$.

izing these groupings. The distinction between activity indices is affirmed by the fact that no item loaded highly on to more than one factor. Hence, the resultant factor patterns are clearly distinguishable from one another and may justifiably be considered as categories of activity.

The mean frequency of participation scores for the four activity types, for the total population and both men and women, are displayed in Table 3. Significant differences in frequency means between men and women are determined by t-test results which are also presented. Taiwanese elderly men participate in social activities most often (mean of 2.62) followed by physical activities (mean of 2.27). Women display highest frequency scores for social (mean of 2.48) and contemplative activities (mean of 2.04).

The hypothesis that women participate in social and indoor activities more than men is only partially confirmed. In fact, men display higher participation scores in the categories of physical, creative and social activity. Women score higher in terms of contemplative activities only and display surprisingly low participation in creative pursuits (mean of 1.16). All $t$ values are significant at 0.01 level.

In order to more clearly determine differences in types of leisure participation of elderly men and women, Table 3 also presents mean scores of individual activities and the percent who participate at least weekly and daily 
in these pursuits. Again, $t$ values determine level of significance. It is clear from these results that in Taiwan men participate in recreation at a much higher rate than women. Men score higher participation scores in all activities with the exception of thinking and worshipping, the two most sedentary activities listed. However, the difference in thinking scores are not significant at 0.01 level.

Looking at the percent who participate in individual activities daily and at least weekly provides further evidence that men are much more active than women. For instance, while almost $1 / 2$ of men read on a daily basis, the same can be said for only $12 \%$ of women. Some of this difference can certainly be attributed to variations in levels of education between genders since men have, on average, a substantially greater number of years of formal schooling. This suggests that men and women possess varying opportunities for the participation in leisure pursuits which may explain some of the observed differences. Only in terms of worshipping is it clear that women outparticipate men. Twenty-eight percent of women compared to $17 \%$ of men worship daily. Variation in this activity may also be a reflection of differences in opportunities to participate in a wider range of leisure activities.

The types of leisure activities preferred differ only somewhat. For example, despite lower overall participation rates, women walk and socialize relatively often. These two activities are also popular among men. Low participation rates are found among both men and women in terms of playing games, hobbies and handicrafts. The two most noticeable differences are more frequent female participation in worshipping and much lower participation in reading.

The third hypothesis is an important one, and states that overall leisure activity enhances the well-being of elderly. In this analysis, the influence of different types of activities on Taiwanese is considered. The activity types are those derived from the factor analysis procedure reviewed above. First, we look at the bivariate relationship. Participation scores are divided into four equal categories for heuristic purposes, with the lowest category representing those who score between 1.00 and 1.74 in the particular leisure activity index, and so on. Since men and women are hypothesized to react differently to different types of leisure activities, the relationship is viewed separately for each gender. Table 4, therefore, presents mean well-being scores for both men and women given levels of participation in the four leisure activity types and a oneway analysis of variance to test for significance.

For both men and women, physical activity appears to be strongly and positively related to well-being. Mean well-being scores for men increase from a low of 5.6 for those in the lowest level of physical participation, to a high of 7.6 for those in the highest category. For women, the increase is linear as well, and rises from a low of 5.3 to a high of 7.2. Both creative and social 
Table 4. Mean well-being scores by level of leisure activities and gender and a oneway analysis of variance

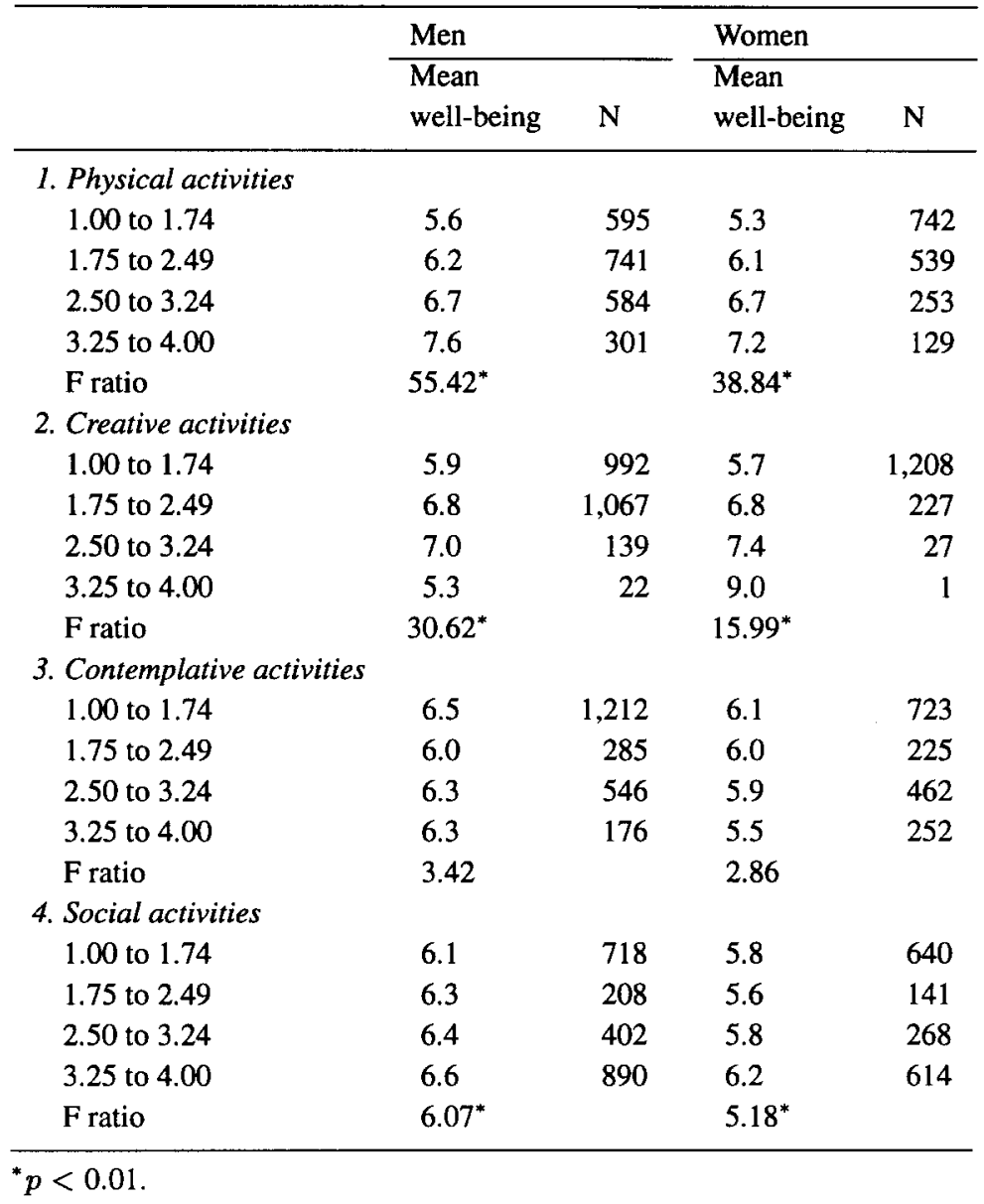

activities also appear to be positively related for both men and women, but to a lesser degree than physical activity. The most distinct difference between the genders appears in the category contemplative activity. Here, well-being scores display little change for men between participation categories, but a declining trend for women.

Although these bivariate results suggest statistically significant associations, it is necessary to control for a number of other variables which have, in the past, been shown to influence well-being. For instance, health status is an important determinant of well-being. It may be that those in better health tend to receive greater benefit from physical activity than those in poorer health. Those with higher education or greater income may be able to better take 
Table 5. Ordinary least squares regression standardized beta coefficients

\begin{tabular}{|c|c|c|c|c|}
\hline & \multicolumn{2}{|l|}{ Men } & \multicolumn{2}{|l|}{ Women } \\
\hline & Model 1 & Model 2 & Model 1 & Model 2 \\
\hline \multicolumn{5}{|l|}{ Demographic variables } \\
\hline Age & $0.12^{*}$ & $0.09^{*}$ & $0.07^{*}$ & 0.03 \\
\hline Marital status $(1=$ married $)$ & $0.11^{*}$ & $0.11^{*}$ & -0.02 & -0.01 \\
\hline Income level & $0.12^{*}$ & $0.11^{*}$ & $0.09^{*}$ & $0.09^{*}$ \\
\hline Years of formal education & 0.04 & 0.03 & $0.07^{*}$ & $0.08^{*}$ \\
\hline \multicolumn{5}{|l|}{ Health status variables } \\
\hline Number of conditions & $-0.16^{*}$ & - & $-0.01^{*}$ & - \\
\hline ADL difficulties index & $-0.14^{*}$ & - & $-0.16^{*}$ & - \\
\hline Self-assessed health & - & $-0.26^{*}$ & - & $-0.27^{*}$ \\
\hline \multicolumn{5}{|l|}{ Social network variables } \\
\hline Satisfaction with contact & $0.15^{*}$ & $0.15^{*}$ & $0.25^{*}$ & $0.24^{*}$ \\
\hline Household size & $0.10^{*}$ & $0.10^{*}$ & $0.10^{*}$ & $0.08^{*}$ \\
\hline \multicolumn{5}{|l|}{ Activity variables } \\
\hline Physical activities & $0.14^{*}$ & $0.15^{*}$ & $0.12^{*}$ & $0.12^{*}$ \\
\hline Creative activities & 0.02 & 0.01 & 0.02 & -0.01 \\
\hline Contemplative activities & -0.04 & -0.04 & $-0.08^{*}$ & $-0.09^{*}$ \\
\hline Social activities & 0.05 & 0.05 & 0.02 & 0.02 \\
\hline $\mathrm{R}^{2}$ & 0.22 & 0.23 & 0.22 & 0.25 \\
\hline F & $51.62^{*}$ & $59.02^{*}$ & $38.07^{*}$ & $48.68^{*}$ \\
\hline
\end{tabular}

${ }^{*} p<0.01$.

advantage of creative pursuits, while those with a larger and more satisfying social network may benefit more from social activities. Table 5 displays the results of ordinary least squares regression equations to determine the influence of leisure activity on well-being for men and women separately. Collinearity diagnostics and a high correlation between self-assessed health and the other two indicators of health status suggest that the former variable may be collinear, and therefore models 1 and 2 display regression results using either self-assessed health or both ADL difficulties and number of chronic conditions. The explained variance is slightly higher in model 2 for both men and women ( 23 and $25 \%$ respectively). The only substantive difference between the two models occurs with age being a significant predictor of well-being for women in the first model but insignificant when controlling for self-assessed health.

Not surprisingly, well-being is significantly influenced by health status for both men and women. For instance, the coefficient for self-assessed health, in Equation 2, is highest in both cases, while the two other health status variables also display relatively high correlations in Equation 1. Both social network 
Table 6. Pearson correlation coefficients of leisure activity types

\begin{tabular}{llcll}
\hline & Physical & Creative & Contemplative & Social \\
\hline Physical & 1.00 & & & \\
Creative & $0.30^{*}$ & 1.00 & & \\
Contemplative & 0.03 & -0.04 & 1.00 & \\
Social & $0.22^{*}$ & $0.07^{*}$ & $0.07^{*}$ & 1.00 \\
${ }^{*} p<0.01$ & & & &
\end{tabular}

variables, size of household and satisfaction with contact, are significantly related to well-being, however, the latter variable is an extremely strong predictor for women. As well, income displays positive associations for both genders.

There are a couple of interesting differences between genders considering the demographic variables. Married men display higher well-being scores, where marital status is an insignificant predictor for women. Conversely, women seem to benefit from higher education, while for men, education has no influence. Finally, age is significant for men in both equations.

When controlling for other factors, only two of the four activity types, physical and contemplative, display significant relationships with well-being for women, and only one, physical activity, for men. For men, contemplative and social activity nears significance but does not meet a $p<0.01$ criteria. Given the number of cases in this study, these coefficients are less than substantial. The influence of physical activity is strongly positive in both cases, verifying its beneficial influence for elderly in Taiwan. The influence of contemplative activities for women, although significant, is inverse. These results run contrary to much of the research conducted in the West. First, physical activity is generally thought to have a greater positive effect on men than women. Further, social activity is thought to benefit women to a substantial degree. This variable has no influence in Taiwan.

It is interesting that creative activity, which appeared to have some bivariate association with well-being, is insignificant when controlling for other factors. It is also noteworthy that contemplative activity has a counter effective influence on women. The possible reasons for this will be discussed in the closing section, but the varying influences of different activity types certainly do suggest that each represents a different domain of leisure. In order to clarify this point, Table 6 presents Pearson correlation coefficients for participation rates of the different activity types. It should be noted that while participation in physical activity is strongly related to both social and creative pursuits, participation in contemplative activity is not related to physical or creative activity, and related only slightly to social activity. Those who use time for 
contemplation, therefore, are not necessarily active recreational users. Given prior evidence presented above, this would seem to make sense, since worshipping and thinking are the only pursuits in which women out-participate men, suggesting that women, or others who spend a good deal of time in contemplative pursuits, either do not have the time, interest, ability or opportunity to pursue other activities.

\section{Discussion}

This analysis used a sample of Taiwanese elders and attempted to test four hypotheses regarding activity among the elderly which have been developed in the West. The results were mixed. The first hypothesis stated that activity is not a unidimensional construct. The use of a factor analysis provided support for this hypothesis. Four activity types were established: physical, creative, contemplative and social.

The second hypothesis stated that men and women tend to participate in different types of leisure activities. This hypothesis is only partially supported. In fact, the relationship in Taiwan appears to be that women, overall, participate much less frequently in recreational activities, although most of their preferred pursuits are similar to those of men. For instance, considering women and men separately, each participate in walking and socializing relatively often, however, mean participation scores for men are significantly higher than for women in all individual activities, and all activity types, except for those which can be defined as contemplative. Men in Taiwan, therefore, are simply more active than women in physical, creative and social recreational pursuits.

In the West, differences in leisure activity participation between men and women have been explained as a function of socialization patterns and role expectations (Keith 1980; Morgan et al. 1991). If a similar interpretation is used for the Taiwan data, it may be suggested that the role of women is not to engage in free-time pursuits to the same degree as men. It may be that activity for women is more imposed and they are involved in the instrumental tasks of maintaining the house. Household sizes in Taiwan are quite large compared to those in the USA, or any other Western country. Children often live with their parents. If women pursue the traditional tasks of housekeeping, there is less time and opportunity for them to engage in leisure.

Twenty-eight percent of women in this study reported daily worship, while $37 \%$ reported engaging in this activity weekly. These numbers represent the third most popular activity for women. Only socializing and walking are more frequent activities for women, and only slightly so. Men, on the other hand, report walking, gardening, reading and socializing more often 
than either of the contemplative activities and the participation rates of these non-contemplative pursuits are much higher than the contemplative ones. In conclusion, the only leisure activities in which women out-participate men are contemplative ones (worshipping and thinking).

The third hypothesis stated that overall, leisure serves to enhance the wellbeing of the elderly. Looking at the entire population, mean well-being scores certainly increase with the level of participation in physical, social and creative activities. Physical activity showed the strongest relationship, and the only one to remain after controlling for other factors. Contemplative activities display a strong negative influence on women but have less impact on men. Support for this hypothesis in the Taiwan case, therefore, depends upon the specific activity type, with physical activity having the greatest benefit to well-being.

The final hypothesis stated that there are gender differences in the influences of leisure activity on well-being with women benefitting from social activity and men benefitting from physical activity. This hypothesis is verified for men, but not in the case of women. The only difference found between the genders is the negative relationship between contemplative activity and well-being for women.

We are left to speculate as to why contemplative activity appears to be an impediment to successful aging in Taiwan, particularly among women. One explanation can rely on Activity Theory and its emphasis on role enhancement. The theory assumes that activities which are solitary in nature add less to well-being than others since, in acting alone, there is little opportunity for the role support necessary in establishing a positive self-concept (Lemon, Bengtson \& Peterson 1972; Knapp 1977). Spending recreation time in contemplation would be the most solitary way of pursuing leisure. One would then expect those who spend much time in contemplation and little time engaging in other leisure activities gain little from their free-time pursuits. Moreover, Morgan et al. (1991) posed that women are less likely to select freely the activities in which they engage. If this is the case in Taiwan, women are forced to engage in more solitary pursuits, which have, in the West, been shown to have a minimal impact on well-being (Knapp 1977; Longino \& Kart 1982).

We can certainly infer from these data that some women in Taiwan have little opportunity to engage in pursuits other than those which are categorized as contemplative in nature. For example, their disadvantage in education may pose barriers to some activities, such as reading, and time may be an overall factor. It may be these women, in particular, who are least likely to gain from leisure activity involvement. To go a step further, the data suggest that contemplative activity, in fact, reduces sense of self for women in Taiwan. In spending time alone and in worship, an individual may be relying on 
an invisible or supernatural other rather than enhancing their image through more active participation with their social network or gaining a sense of self-efficacy and mastery over their physical environment. The traditional roles of women in Taiwan may impose that their leisure activity is somewhat confined, and hence a negative self-image may develop in those who only have the opportunity for contemplative activities. It is ironic, then, that while women may be the ones best served from the reinforcement gained in active participation, they are left with the pursuit of contemplation only, which may be an impediment to well-being.

Other explanations may be advanced for this negative relationship. For instance, it is quite possible that those who engage in contemplative activities are already more predisposed to negative life satisfaction. In other words, the relationship may be reciprocal, where having a low life satisfaction promotes contemplation and worship in the hopes that such activity will improve things. Given the nature of cross-sectional data, such conclusions cannot be dismissed. On the other hand, it may be that contemplation negatively influences well-being only when it is the only activity being pursued. If contemplation is combined with other diverse interests, the negative influence of solitary activity may be minimal, and since women are less active overall, they may be the ones who engage in contemplation only. These explanations suggest that there may be important relationships between worship and self image and between overall activity level and self-esteem. Although empirical testing of these possibilities are beyond the scope of this paper, they do provide the impetus for further analyses.

Although the analysis tends to support the notion that emotional well-being may be enhanced through physical activity, which tends to produce feelings of competency, accomplishment, self-efficacy and mastery over one's environment, similar support for the impact of other leisure activity types is lacking. Subjective, rather than objective, integration has often been found to have the most pronounced influence on well-being (Steinkamp \& Kelly 1987; Liang, Dvorkin, Kahana \& Mazian 1980). In the present analysis, satisfaction with contact, a measure which may account for a perception of the quality of social integration, may explain some of the initially observed bivariate relationship between creative and social activity and well-being. Both of these activity types appeared to increase well-being when viewed on their own, but were insignificant in the multivariate analysis. If social and creative activity influences well-being positively only inasmuch as subjective integration is enhanced, the influence of frequency of participation in the activity would diminish when subjective measures of interaction, like satisfaction with contact, are taken into account. Subjective integration may therefore explain the 
lack of significant findings between social and cultural activity and well-being in multivariate analyses.

Moreover, differences between the way men and women in Taiwan react to leisure activity participation may also depend upon differences in their perception of social integration. For women, satisfaction with contact is as important a predictor of well-being as self-assessed health. Its effect is significant, though somewhat weaker, for men. This may be quite meaningful in the present context. Since household sizes tend to be large and children more often live in the same household as their parents than in the West, women may be more influenced by the quality of contact with their social network. Put another way, because of the spatial nearness of much of ones social network, a subjective feeling of unsatisfactory social integration may play an exceedingly immediate role in the well-being of women in Taiwan. In this case, the quality, and not the quantity, is the important determinant. This conclusion would tend to support research by Steinkamp \& Kelly (1987), who argued that the weakness in the Activity Theory as originally stated is that it ignores the subjective interpretation of social interaction. Further research on the influence of activity should estimate, more carefully, the influence of objective versus subjective social integration of Taiwanese men and women.

In conclusion, this examination of leisure activity involvement for Taiwanese elders both substantiate and refute hypotheses developed in the West. On the one hand, leisure activity is verified to be a multidimensional concept and some positive associations between frequency of leisure activity and well-being were found. On the other hand, men participate in most activities with much greater frequency than women, physical activity was found to have the strongest positive influence on well-being, while contemplative activity, the only pursuit in which women out-participate men, displays a negative effect for women. It was speculated that some of the gender differences may be explained in terms of differences in socialization and role expectations and its influence on self-concept development. The positive influence of physical activity supports the notion of the beneficial aspects of activities which promote feelings of self-efficacy. Hence, although the results only partially confirmed hypotheses developed in the West, previously developed theoretical orientations were found to be useful in speculating on the causes of some of these divergences.

Perhaps what is most important for future research is to directly compare data sources from the West with those in Asia. Future data collection in Asia, and other developing regions, should consider seriously the importance of information on leisure participation and free-time pursuits, since, as a determinant of well-being, activity has substantial import. Although this analysis has attempted to test some commonly cited hypotheses developed in the West, 
it is through a direct comparison of data that the greatest progress in theory building will be made.

\section{Acknowledgments}

This research was conducted as part of 'Rapid demographic change and the welfare of the elderly', sponsored by the US National Institute on Aging (Grant No. AG07637). Organizations collaborating in this research include The Taiwan Provincial Institute of Family Planning and the Population Studies Center, University of Michigan. The authors wish to acknowledge Dr Albert Hermalin for his helpful comments on a previous version of this paper.

\section{References}

Chappell N.L. (1992). Social support and aging. Toronto, Ont.: Butterworths.

Crandall R. (1979). Social interaction, affect and leisure, Journal of Leisure Research 11: $165-181$.

Csikszentmihalyi M. (1994). The consequences of leisure for mental health. In D.M. Compton \& S.E. Iso-Ahola (eds.), Leisure and mental health, Vol. 1 (pp. 34-41). Park City, UT: Family Development.

DeCarlo T.J. (1974). Recreation participation patterns and successful aging, Journal of Gerontology 29: 416-422.

Doyle D. \& Forehand M.J. (1984). Life satisfaction and old age: A reexamination, Research on Aging 6: 432-448.

Duff R.W. \& Hong L.K. (1982). Quality and quantity of social interactions in the life satisfaction of older Americans, Sociology and Social Research 66: 418-434.

Fly J.W., Reinhart G.R. \& Hamby R. (1981). Leisure activity and adjustment in retirement, Sociological Spectrum 1: 135-144.

Iso-Ahola, S.E. (1989). Motivation for leisure. In E.L. Jackson \& T. Burton (eds.), Leisure and recreation. State College, PA: Venture.

Iso-Ahola S.E. (1994). Leisure lifestyle and health. In D.M. Compton \& S.E. Iso-Ahola (eds.), Leisure and mental health, Vol. 1 (pp. 42-60). Park City, UT: Family Development.

Iso-Ahola S.E., LaVerde D. \& Graefe A.R. (1989). Perceived competence as a mediator of the relationship between high risk sports participation and self-esteem, Journal of Leisure Research 21: 32-39.

Kaufman J.E. (1988). Leisure and anxiety: A study of retirees, Activities, Adaptation and Aging 1: 3-10.

Keith P.M. (1980). Life changes, leisure activities and well being among very old men and women, Activities, Adaptation and Aging 1: 67-75.

Kennedy C.A., King J.A. \& Muraco W.A. (1983). The relative strength of health as a predictor of life satisfaction, International Social Science Review 58: 97-102.

Knapp M.R.J. (1977). The activity theory of aging. The Gerontologist 17: 553-559.

Lee G.R. (1978). Marriage and morale in later life, Journal of Marriage and the Family 40: 131-139.

Lemon B.W., Bengtson V.L. \& Peterson J.A. (1972). An exploration of the activity theory of aging: Activity types and life satisfaction among in-movers to a retirement community, Journal of Gerontology 27: 511-523. 
Liang J., Dvorkin L., Kahana E. \& Mazian F. (1980). Social integration and morale: A reexamination, Journal of Gerontology 35: 746-757.

Lilley J. \& Jackson L.T. (1990). The value of activities: Establishing a foundation for cost effectiveness: A review of the literature, Activities, Adaptation and Aging 14: 5-20.

Lomranz J., Bergman S., Eyal N. \& Shmotkin D. (1988). Indoor and outdoor activities of aged women and men as related to depression and well-being, International Journal of Aging and Human Development 26: 303-314.

Longino C.F. Jr. \& Kart C.S. (1982). Explicating activity theory: A formal replication, Journal of Gerontology 37: 713-722.

Markides K.S. \& Martin H.W. (1979). A causal model of life satisfaction among the elderly, Journal of Gerontology 34: 86-93.

McKenzie B. \& Campbell J. (1987). Race, socioeconomic status and the subjective well-being of older Americans, International Journal of Aging and Human Development 25: 43-61.

Morgan K. Dallosso H.D., Bussey E.J., Ehrahim S., Fentem P.H. \& Arie T.H.D. (1991). Customary physical activity, psychological well-being and successful aging, Ageing and Society 11: $399-415$.

Palmore E. \& Kivett V. (1977). Changes in life satisfaction: A longitudinal study of persons aged 46-70, Journal of Gerontology 32: 311-316.

Pohjolainen P. (1991). Social participation and life-style: A longitudinal and cohort study, Journal of Cross-Cultural Gerontology 6: 109-117.

Russell R.V. (1990). Recreation and quality of life in old age: A causal analysis, The Journal of Applied Gerontology 9: 77-90.

Steinkamp M.W. \& Kelly J.R. (1987). Social integration, leisure activity, and life satisfaction in older adults: Activity theory revisited, International Journal of Aging and Human Development 25: 293-307.

Stewart A.L. \& King A.C. (1991). Evaluating the efficacy of physical activity for influencing quality-of-life outcomes in older adults, Annals of Behavioral Medicine 13: 108-116.

Zimmer Z., Hickey T. \& Searle M.S. (1995). Activity participation and well-being among older people with arthritis, The Gerontologist 35: 463-471.

Address for correspondence: Zachary Zimmer, MD, Population Studies Center, University of Michigan, 1225 South University Avenue, Ann Arbor, MI 48104-2590, USA

Phone: (313) 930 0820; Fax: (313) 998 7415; E-mail: zzimmer@umich.edu 